\title{
A survey of resilience, burnout, and tolerance of uncertainty in Australian general practice registrars
}

\author{
Georga PE Cooke ${ }^{1 *}$, Jenny A Doust ${ }^{1}$ and Michael C Steele ${ }^{2}$
}

\begin{abstract}
Background: Burnout and intolerance of uncertainty have been linked to low job satisfaction and lower quality patient care. While resilience is related to these concepts, no study has examined these three concepts in a cohort of doctors. The objective of this study was to measure resilience, burnout, compassion satisfaction, personal meaning in patient care and intolerance of uncertainty in Australian general practice (GP) registrars.

Methods: We conducted a paper-based cross-sectional survey of GP registrars in Australia from June to July 2010, recruited from a newsletter item or registrar education events. Survey measures included the Resilience Scale-14, a single-item scale for burnout, Professional Quality of Life (ProQOL) scale, Personal Meaning in Patient Care scale, Intolerance of Uncertainty-12 scale, and Physician Response to Uncertainty scale.

Results: 128 GP registrars responded (response rate 90\%). Fourteen percent of registrars were found to be at risk of burnout using the single-item scale for burnout, but none met the criteria for burnout using the ProQOL scale. Secondary traumatic stress, general intolerance of uncertainty, anxiety due to clinical uncertainty and reluctance to disclose uncertainty to patients were associated with being at higher risk of burnout, but sex, age, practice location, training duration, years since graduation, and reluctance to disclose uncertainty to physicians were not. Only ten percent of registrars had high resilience scores. Resilience was positively associated with compassion satisfaction and personal meaning in patient care. Resilience was negatively associated with burnout, secondary traumatic stress, inhibitory anxiety, general intolerance to uncertainty, concern about bad outcomes and reluctance to disclose uncertainty to patients.
\end{abstract}

Conclusions: GP registrars in this survey showed a lower level of burnout than in other recent surveys of the broader junior doctor population in both Australia and overseas. Resilience was also lower than might be expected of a satisfied and professionally successful cohort.

Keywords: Adaptation, Psychological, Burnout, Professional, Job satisfaction, Uncertainty

\section{Background}

Doctors are widely reported to be unhappy and burntout [1]. Burnout is a psychological "syndrome of emotional exhaustion, depersonalization, and reduced personal accomplishment that can occur among individuals who work with people" [2]. The onset of burnout is often in the early postgraduate period [3]. Willcock found that the

\footnotetext{
* Correspondence: gcooke@bond.edu.au

${ }^{1}$ Centre for Research in Evidence-Based Practice, Bond University, Gold Coast, Queensland, Australia

Full list of author information is available at the end of the article
}

prevalence of burnout increased steadily through the first year of a medical practitioner's career [4].

A doctor's affective reactions to clinical uncertainty, bad patient outcomes and coping behaviours, as measured by the Physician Response to Uncertainty scale, impacts on how they respond to stress [5]. Higher intolerance of clinical uncertainty has been linked to burnout in one study of primary care physicians [6] and one study of emergency physicians [7] in the USA. General practitioners and other primary care practitioners who see a high proportion of undifferentiated illness are particularly exposed to uncertainty in decision making. Doctors with

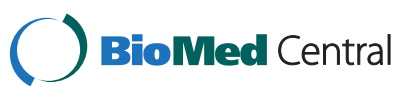


higher anxiety about uncertainty tend to have higher costs of investigation and treatment [8].

With the rise of positive psychology, resilience and positive adaptation have become a field of research in themselves. Resilience has various definitions but is broadly accepted to mean a "dynamic, evolving process of positive attitudes and effective strategies" that we employ in response to life stressors [9]. The value of resilience is widely acknowledged in nursing literature [10] but it has attracted much less attention in medical circles. One study demonstrated that resilience is associated with academic productivity in minority faculty members in a US academic health centre [11]. Keeton used an unvalidated scale of resilience to examine predictors of career satisfaction in a population of US physicians [12]. Recently, the concept of vicarious resilience, which acknowledges the "complex potential of therapeutic work both to fatigue and to heal" [13] has come to the attention of psychotherapists. Junior doctors are similarly exposed to caring for people who appear to thrive in life despite ill health and suffering. However, vicarious resilience in doctors has not yet been the focus of research activity.

To summarise, early in their career, junior doctors must face being held accountable for their medical decisions for the first time. They must learn to manage uncertainty, but it is also when they are vulnerable to burnout. We hypothesised that burnout, resilience and tolerance of uncertainty are likely to be related in junior doctors. However, we were unable to identify a study which explored if a relationship existed between these three concepts. The aim of this study was to measure the prevalence of resilience, burnout, compassion satisfaction and tolerance of uncertainty in Australian GP registrars, to determine if there are relationships between these concepts in this practice group. We also aimed to determine if demographic factors and personal meaning derived from patient care were associated with burnout in this group.

\section{Methods}

We conducted a paper-based survey of Australian GP registrars. This study had ethics approval from the Bond University Human Research Ethics Committee.

\section{Participants}

Australian GP registrars were eligible for participation if they had completed at least 2 years of hospital-based posts and at least three months in GP rotations. In Australia, GP registrars are doctors on a formal training program to become independently registered general practitioners, known as family doctors in some other parts of the world. Before commencing the program, GP registrars must have completed at least one-year of a hospital based internship. Once accepted on the program, the most common pathway involves three years of supervised training: one year of hospital training, 18 months within community general practice and 6 months of extended skills training. On completion of training time and other requirements, including a fellowship examination, registrars become qualified to practise independently as general practitioners. Extended pathways exist for registrars wishing to gain advanced skills for rural general practice.

\section{Recruitment}

We used a convenience sample and recruited participants by advertising in a GP registrar newsletter and by approaching registrars at education events put on by four Regional Training Providers (RTPs) in Queensland, Victoria, South Australia and the Northern Territory who deliver GP registrar training in Australia. With the permission of the Directors of Education at each RTP, the primary researcher attended education events to distribute the survey. The recruitment period was June 2010.

\section{Setting and procedure}

Participants recruited at education events could complete the survey at the event or return it via the mail at a later date. We distributed the survey with a reply-paid envelope, together with an introductory letter and explanatory statement. We did not offer incentives or inducements.

\section{Survey instruments}

Our survey consisted of several validated scales, including for burnout, resilience, tolerance of uncertainty and personal meaning in patient care (Table 1). We also included questions about demographics and progress through GP training.

The primary measure of burnout was the single-item measure of burnout [14-16] which has been validated against the Maslach Burnout Inventory emotional exhaustion subscale, a widely used scale for burnout, in a cohort of physicians [17] and Australian clinical cancer workers [18]. This measure consists of five statements (Table 2), with participants asked to select the most relevant statement for them. Participants were divided into 'low risk of burnout' if they selected statement 1 or 2 , and 'high risk' if they selected statements 3-5, as described by Rohland [17]. The Professional Quality of Life (ProQOL) scale was also used to measure burnout, together with secondary traumatic stress and compassion satisfaction [19]. The ProQOL subscale for burnout has 10 items. The ProQOL subscale is divided into low, average and high scores for burnout according to predefined cut-offs.

The Resilience Scale-14 measures global resilience, comprised of five characteristics: purpose, perseverance, self-reliance, equanimity and existential aloneness [20]. The 14 items are scored on a likert scale, which are summed to arrive at a global score. The authors divide 
Table 1 Instruments included in survey

\begin{tabular}{ll}
\hline Name of instrument & Range of possible scores \\
\hline Single item measure of burnout & 1 to 5 \\
\hline Professional Quality of Life (ProQOL) & 10 to 50 \\
\hline Compassion satisfaction (CS) & 10 to 50 \\
\hline Burnout & 10 to 50 \\
\hline Secondary Traumatic Stress (STS) & 14 to 98 \\
\hline Resilience Scale - 14 & 6 to 24 \\
\hline Personal Meaning in Patient Care & 7 to 35 \\
\hline Intolerance to Uncertainty Scale - 12 & 5 to 25 \\
\hline Prospective anxiety & 12 to 60 \\
\hline Inhibitory anxiety & 5 to 30 \\
\hline \begin{tabular}{l} 
Physician Reactions to Uncertainty \\
\hline Anxiety due to uncertainty
\end{tabular} & 3 to 18 \\
\hline Concern about bad outcomes & 5 to 30 \\
\hline $\begin{array}{l}\text { Reluctance to disclose uncertainty to } \\
\text { patients }\end{array}$ & 2 to 12 \\
\hline $\begin{array}{l}\text { Reluctance to disclose uncertainty to } \\
\text { physicians }\end{array}$
\end{tabular}

the global score into three categories. For simplicity, we refer to these as low (L), low-moderate $(\mathrm{M})$, and high $(\mathrm{H})$ resilience. The Personal Meaning in Patient Care scale, consisting of six items, was validated in clinicians working in genetics [21]. High scores are associated with low burnout, gratitude and professional satisfaction.

We measured intolerance of uncertainty both generally and in the clinical context by using two separate scales. The Intolerance of Uncertainty-12 (IUS-12) scale has twelve items each scored on a likert scale of 5. The IUS-12 can be divided into two subscales; one for prospective anxiety (fear and anxiety based on future events) (seven items) and one for inhibitory anxiety (uncertainty which inhibits action or experience) (five items) [22]. The Physician Reactions to Uncertainty scale measures affective reactions to

Table 2 Statements in single item measure of burnout [14-16]

\begin{tabular}{ll}
$\begin{array}{l}\text { Response } \\
\text { number }\end{array}$ & Statement \\
\hline 1 & I enjoy my work. I have no symptoms of burnout. \\
& Occasionally I am under stress, and I don't always have \\
as much energy as I once did, but I don't feel burned \\
out.
\end{tabular}

uncertainty in clinical situations, using four subscales which are summarised in Table 1 [5].

\section{Analysis}

Participants were categorised as being at high or low risk of burnout using the single-item measure of burnout. Relationships between burnout and non-burnout groups were determined using t-tests for continuous data and $x^{2}$ tests for categorical data. For the resilience analysis, where low, low-moderate, and high resilience could not be assumed to be normally distributed, a Kruskal-Wallis test was used instead of an ANOVA. Cronbach's $\alpha$ was used to measure reliability. All analyses were conducted with SPSS software.

\section{Results}

We distributed 148 surveys and received 128 responses (90\% response rate). 122 surveys were distributed at education events (98\%). The demographic and geographic distribution of respondents (Table 3) was similar to the Australian GP registrar cohort [23]. Most registrars felt that their previous experience had prepared them well for general practice $(80 \%)$ and felt well supervised in their training (89\%).

Eighteen registrars (14\%) were at risk of burnout when using the single-item burnout scale. Using the ProQOL burnout subscale, no registrars had scores suggesting a high

\section{Table 3 Participant Characteristics}

\begin{tabular}{ll}
\hline Participant characteristics & $\%$ \\
\hline Sex & 67 \\
$\quad$ Female & \\
Age & 44 \\
$20-29$ & 41 \\
$30-39$ & 11 \\
$40-49$ & 4
\end{tabular}

Years since graduation

3

428

$5-16$

6 to $10 \quad 25$

$11+\quad 15$

GP Training Term

Term 1 (0-6 months full time equivalent) 66

Term 2 (7-12 months full time equivalent) 6

Term 3 (13-18 months full time equivalent) 27

Other 1

Practice Location

Metropolitan 
risk of burnout, although those who were at high risk of burnout on the single-item scale also had statistically significantly higher scores for burnout on the ProQOL ( $\mathrm{p}<0.001)$. The internal reliability of the ProQOL, Intolerance of Uncertainty-12 scale and Physician Response to Uncertainty scale were good to excellent (Cronbach's $\alpha>0.75$ ) and were consistent with the results in validation studies.

Sex, age, practice location and time in general practice showed no relationship with burnout (Table 4). Burnout was associated with secondary traumatic stress but not with compassion satisfaction. Lower resilience, lower personal meaning in patient care, intolerance of uncertainty, prospective anxiety, inhibitory anxiety, anxiety due to (clinical) uncertainty and reluctance to disclose uncertainty to patients were associated with burnout (Table 5).

Most registrars had scores which fell in the low-moderate resilience range $(82 \%)$. Only ten registrars $(8 \%)$ had high resilience scores and thirteen registrars (10\%) had a low resilience score. High resilience was associated with low burnout $(\mathrm{P}<0.001)$ and low general intolerance to uncertainty $(\mathrm{P}=0.049)$. In relation to clinical uncertainty, resilience was associated with less concern about bad outcomes $(P=0.001)$ and less reluctance to disclose uncertainty to patients $(P=0.007)$. However, no relationship was found between reluctance to disclose uncertainty to other physicians $(\mathrm{P}=0.1)$ and with anxiety due to uncertainty $(\mathrm{P}=0.5)$.

\section{Discussion}

Our survey found a lower prevalence of burnout in GP registrars (14\% using the single-item scale and none using the ProQOL burnout subscale) than other recent surveys of the Australian junior doctor population (31 - 75\%) $[4,24,25]$. Interestingly, we found no relationship between a registrar's duration of GP experience and burnout. While negative responses to clinical uncertainty have been linked with burnout in other research [6,7], the relationship between lower resilience and lower tolerance of clinical uncertainty has not been demonstrated before. We are also not aware that a doctor's general response to uncertainty (IUS-12) has been linked with burnout or resilience previously. We found no relationship between burnout or resilience and reluctance to disclose uncertainty to

Table 4 Relationship between demographic factors and risk of burnout

\begin{tabular}{ll}
\hline Participant characteristic & $\begin{array}{l}\boldsymbol{X} \text { 2 test of independence } \\
\text { ( } \mathbf{p} \text { value) }\end{array}$ \\
\hline Sex & 0.96 \\
Age & 0.80 \\
Years since graduation & 0.74 \\
GP Term & 0.65 \\
Practice Location (rural or metropolitan) & 0.19 \\
\hline
\end{tabular}

Table 5 The relationship of burnout to compassion satisfaction, secondary traumatic stress, personal meaning in patient care and intolerance of uncertainty in Australian GP registrars

\begin{tabular}{|c|c|c|c|}
\hline & $\begin{array}{c}\text { Low } \\
\text { burnout } \\
(n=109) \\
\text { Mean (SD) }\end{array}$ & $\begin{array}{c}\text { High } \\
\text { burnout } \\
(n=18) \\
\text { Mean (SD) }\end{array}$ & $p$ value \\
\hline \multicolumn{4}{|l|}{ ProQOL } \\
\hline Compassion satisfaction & $36.8(4.4)$ & $33.9(5.9)$ & 0.63 \\
\hline Secondary traumatic stress & $20.8(4.0)$ & $24.2(4.6)$ & $0.002 *$ \\
\hline \multicolumn{4}{|l|}{$\begin{array}{l}\text { Intolerance of Uncertainty } \\
\text { Scale }-12\end{array}$} \\
\hline Prospective anxiety & $19.7(4.6)$ & $23.3(6.5)$ & $0.005 *$ \\
\hline Inhibitory anxiety & $10.5(3.8)$ & $13.3(4.3)$ & $0.005 *$ \\
\hline Total & $30.2(7.2)$ & $36.6(9.8)$ & $0.001 *$ \\
\hline Resilience Scale -14 & $75.8(12.5)$ & $67.7(10.0)$ & $0.010 *$ \\
\hline $\begin{array}{l}\text { Personal meaning in } \\
\text { patient care }\end{array}$ & $16.8(3.2)$ & $14.7(3.3)$ & $0.014 *$ \\
\hline \multicolumn{4}{|l|}{$\begin{array}{l}\text { Physician response to } \\
\text { uncertainty scale }\end{array}$} \\
\hline Anxiety due to uncertainty & $18.8(5.0)$ & $21.7(4.3)$ & $0.02 *$ \\
\hline Concern about bad outcomes & $11.5(3.4)$ & $13.0(4.0)$ & 0.10 \\
\hline $\begin{array}{l}\text { Reluctance to disclose } \\
\text { uncertainty to patients }\end{array}$ & $13.6(3.8)$ & $15.7(3.3)$ & $0.03^{*}$ \\
\hline $\begin{array}{l}\text { Reluctance to disclose } \\
\text { uncertainty to physicians }\end{array}$ & $4.0(1.9)$ & $4.5(2.1)$ & 0.30 \\
\hline
\end{tabular}

*statistically significant result.

physicians $(\mathrm{p}=0.30)$; a reassuring finding as GP registrars will generally need to seek help when they encounter unfamiliar situations.

Our study had several strengths. We achieved a very high response rate and our sample was representative of the GP registrar population when compared with the most comprehensive data available [23]. The limitations of our study are common to most burnout literature. While the single-item questionnaire has been validated in a cohort of physicians, it may not be sufficiently reliable. However, our second measure of burnout, the 10 item ProQOL scale, is likely to be sensitive and has been widely used in previous research and showed a similar direction of results. Also, the surveys were distributed at educational events, where registrars may feel more positive towards their work compared to a day of usual clinical practice.

Low response rates and responder bias may explain the higher level of burnout (31 - 75\%) reported in other studies $[4,24,25]$. Our results are surprising but are in line with the validation study of the single-item measure of burnout in US physicians, which found that $23 \%$ of physicians were burnt-out [17], and with a recent survey of GP registrars that showed $10 \%$ were mildly or moderately depressed or anxious [26]. GP registrars may be less burnt-out than their hospital colleagues during training, or our results may 
represent a broader trend where junior doctors are not as burnt-out as their more senior colleagues.

Burnout has significant consequences for a doctor's own health and that of their patients. For example, internal medicine trainees who are burnt-out are more likely to selfreport suboptimal patient care [27] and medical errors [8]. Burnout is also linked with the intention to leave clinical medicine [14]. Montgomery [28] has proposed that burnout is the missing link in quality care. Indeed, burnout and physician wellness have been described as neglected quality indicators in medicine [29].

Our study showed burnout in GP registrars is strongly linked with general intolerance of uncertainty. GP training in Australia provides a structured opportunity to intervene to prevent burnout and bolster tolerance of uncertainty. Discussing tolerance of uncertainty and evidence-based management of clinical uncertainty may be a more acceptable approach for registrars, rather than overtly talking about burnout prevention.

Resilience was linked to high compassion satisfaction, low burnout, and a higher tolerance of both general and clinical uncertainty. However, resilience was also lower than might be expected. While it is increasingly acknowledged that teaching and learning about resilience is important in health professional curricula [30], there is scant research about resilience and medical professionals. Jensen identified factors which contribute to physician resilience which can be learnt by physicians (accepting personal limitations, developing self-awareness and limit setting) or addressed structurally within a workplace (practice management style and culture) [9]. A longitudinal study of GP registrars, with adequate response rates, through fellowship and beyond, would be required to explain our findings.

\section{Conclusions}

Overall, our study showed a lower prevalence of burnout than would be expected from recent Australian data. Burnout in GP registrars is also strongly linked with general intolerance of uncertainty. Resilience was also lower than might be expected. Resilience was linked to high compassion satisfaction, low burnout, and a higher tolerance of both general and clinical uncertainty.

\section{Competing interests}

Georga Cooke is the immediate past Registrar Representative on the Royal Australian College of General Practitioners Council. She was employed by General Practice Education and Training (GPET) Ltd as the Registrar Research and Development Officer in 2011, a registrar position which assists with coordinating academic registrar posts in GP training in Australia, and now sits on the GPET Board.

\section{Authors' contributions}

GPEC was chiefly responsible for the conception, design and coordination of the study and analysis, and drafted the manuscript. JAD and MCS participated in the design of the study and helped to draft the manuscript. MCS performed the statistical analysis. All authors have read and approved the final manuscript.

\section{Acknowledgements}

Georga Cooke would like to acknowledge the funding and support provided by the Academic Registrar program of General Practice Education and Training (GPET) Ltd.

\section{Author details}

${ }^{1}$ Centre for Research in Evidence-Based Practice, Bond University, Gold Coast, Queensland, Australia. ${ }^{2}$ Faculty of Business, Bond University, Gold Coast, Queensland, Australia.

Received: 12 January 2012 Accepted: 17 December 2012

Published: 7 January 2013

\section{References}

1. Smith R: Why are doctors so unhappy? Br Med J 2001, 322(7294):1073-1074.

2. Maslach C, Jackson SE, Leiter MP: Maslach burnout inventory manual. 3rd edition. Mind Garden, Menlo Park, California: Consulting Psychologists Press; 1996.

3. Rosen IM, Gimotty PA, Shea JA, Bellini LM: Evolution of sleep quantity, sleep deprivation, mood disturbances, empathy, and burnout among interns. Acad Med 2006, 81(1):82-85.

4. Willcock SM, Daly MG, Tennant CC, Allard BJ: Burnout and psychiatric morbidity in new medical graduates. Med J Aust 2004, 181(7):357-360.

5. Gerrity MS, White KP, DeVellis RF, Dittus RS: Physicians' reactions to uncertainty: refining the constructs and scales. Motiv Emot 1995, 19(3):175-191.

6. Bachman KH, Freeborn DK: HMO physicians' use of referrals. Soc Sci Med 1999, 48(4):547-557.

7. Kuhn G, Goldberg R, Compton S: Tolerance for uncertainty, burnout, and satisfaction with the career of emergency medicine. Ann Emerg Med 2009, 54(1):106-113. e106.

8. West CP, Tan AD, Habermann TM, Sloan JA, Shanafelt TD: Association of resident fatigue and distress with perceived medical errors. JAMA 2009, 302(12):1294-1300.

9. Jensen PM, Trollope-Kumar K, Waters H, Everson J: Building physician resilience. Can Fam Physician 2008, 54(5):722-729.

10. Jackson D, Firtko A, Edenborough M: Personal resilience as a strategy for surviving and thriving in the face of workplace adversity: a literature review. J Adv Nurs 2007, 60(1):1-9.

11. Cora-Bramble D, Zhang K, Castillo-Page L: Minority faculty members' resilience and academic productivity: are they related? Acad Med 2010, 85(9):1492-1498.

12. Keeton K, Fenner DE, Johnson TR, Hayward RA: Predictors of physician career satisfaction, work-life balance, and burnout. Obstet Gynecol 2007, 109(4):949-955.

13. Hernández $P$, Gangsei $D$, Engstrom D: Vicarious resilience: a new concept in work with those who survive trauma. Fam Process 2007, 46(2):229-241.

14. Schmoldt R, Freeborn D, Klevit H: Physician burnout: Recommendations for HMO managers. HMO Practice/HMO Group 1994, 8:58-63.

15. Freeborn DK: Satisfaction, commitment, and psychological well-being among HMO physicians. West J Med 2001, 174(1):13-18.

16. Williams ES, Konrad TR, Linzer M, McMurray J, Pathman DE, Gerrity M, Schwartz MD, Scheckler WE, Van Kirk J, Rhodes E, et al: Refining the measurement of physician job satisfaction: results from the Physician Worklife Survey. SGIM Career Satisfaction Study Group. Society of General Internal Medicine. Med Care 1999, 37(11):1140-1154.

17. Rohland B, Kruse G, Rohrer J: Validation of a single-item measure of burnout against the Maslach Burnout Inventory among physicians. Stress Heal 2004, 20(2):75-79.

18. Hansen V, Girgis A: Can a single question effectively screen for burnout in Australian cancer care workers? BMC Health Serv 2010, 10:341.

19. Stamm B: The Concise ProQOL Manual. 2nd edition. Pocatello: The ProQOL.org; 2010.

20. Wagnild G: A review of the Resilience Scale. J Nurs Meas 2009, 17(2):105-113.

21. Geller G, Bernhardt BA, Carrese J, Rushton CH, Kolodner K: What do clinicians derive from partnering with their patients? A reliable and valid measure of "personal meaning in patient care". Patient Educ Couns 2008, 72(2):293-300.

22. Carleton RN, Norton MA, Asmundson GJ: Fearing the unknown: a short version of the Intolerance of Uncertainty Scale. J Anxiety Disord 2007, 21(1):105-117 
23. Piazza Research, GPET: GP Registrar Satisfaction Survey - annual survey of GP registrars. Australia: Piazza Research Pty Ltd Ph; 2010.

24. Heredia DC, Rhodes CS, English SE, Law DB, MCElrea AC, Honeyball FX: The national Junior Medical Officer Welfare Study: a snapshot of intern life in Australia. Med J Aust 2009, 191(8):445.

25. Markwell AL, Wainer Z: The health and wellbeing of junior doctors: insights from a national survey. Med J Aust 2009, 191(8):441-444.

26. Schattner P, Mazalin D, Pier C, Wainer J, Ling MY: GP registrar well-being: a cross-sectional survey. Asia Pac Fam Med 2010, 9(1):2.

27. Shanafelt T, Bradley K, Wipf J, Back A: Burnout and self-reported patient care in an internal medicine residency program. Ann Intern Med 2002, 136:358-367.

28. Montgomery A, Panagopoulou E, Kehoe I, Valkanos E: Connecting organisational culture and quality of care in the hospital: is job burnout the missing link? J Health Organ Manag 2011, 25(1):108-123.

29. Wallace JE, Lemaire JB, Ghali WA: Physician wellness: a missing quality indicator. Lancet 2009, 374(9702):1714-1721.

30. McAllister M, McKinnon J: The importance of teaching and learning resilience in the health disciplines: a critical review of the literature. Nurse Educ Today 2009, 29(4):371-379.

doi:10.1186/1472-6920-13-2

Cite this article as: Cooke et al:: A survey of resilience, burnout, and tolerance of uncertainty in Australian general practice registrars. $B M C$ Medical Education 2013 13:2.

\section{Submit your next manuscript to BioMed Central and take full advantage of:}

- Convenient online submission

- Thorough peer review

- No space constraints or color figure charges

- Immediate publication on acceptance

- Inclusion in PubMed, CAS, Scopus and Google Scholar

- Research which is freely available for redistribution 